\title{
Assessment of Cost of Quality and its Effects on Manufacturing Performance: A Case Study of Special Ice Company Limited, Ghana
}

\author{
Prince Kelvin Owusu ${ }^{1}$ \& Michael Asare Goh ${ }^{2}$ \\ ${ }^{I}$ Ghana Technology University College, Information Systems Department, Ghana. Email: powusu@ gtuc.edu.gh \\ ${ }^{2}$ Ghana Technology University College, Graduate School, Ghana. Email: ghmchl@ gmail.com
}

DOI: $10.38177 / A J B S R .2020 .2301$

There is an increasing trend in competition on the global market and this has compelled many manufacturing and service companies to revise their understanding of quality. Customers today make informed choices and patronize products and services based on their quality. There are also regulations which are established by government agencies to ensure that products and services are of expected quality that satisfies the needs of the customer. This demand from customers has triggered a need for manufacturing companies to always provide quality products to stay in competition. Provision of quality products has a cost element attached to it. The study was a case study and focused on the assessment of cost of quality and its effect on manufacturing performance. There have been several researches that have shown the relevance of cost of quality assessment in a manufacturing firm. This research looks at cost of quality with specific emphasis on the classical P-A-F (Prevention-Appraisal-Failure) cost model and tries to ascertain its effects on manufacturing performance.

The study focused on Special Ice Company Limited as a case study. The study employed three categories namely, cost of prevention, cost of appraisal and cost of failure as a proxy for cost of quality on the manufacturing performance. A sample of 80 participants was randomly selected for this study. Primary data was collected and analyzed. The findings show that the cost of quality element like cost of external failure and cost of appraisal had a statistically significant impact on the manufacturing performance of the company. A semi-structured interview was also conducted with the Manage Director to further understand the posturing of the top management with regards to the study.

The study recommended that the organization make a conscious effort to sensitize employees to understand the cost of quality and its implications on the manufacturing performance of the company and also appraise their production processes at all times and ensure their entire staff adhere to accepted procedures. Again, the study also recommended that top management get actively involved and make a conscious effort to incorporate the cost of quality in their decision-making process and get all staff to align and adhere to it and also pay close attention to customer complaints act on it to improve on the products.

Keywords: Cost of Quality, Manufacturing performance, Managerial skills, Cost reduction, Quality of service.

\section{Introduction}

High competition and the presence of a globalized business environment in the market has compelled companies to strive to meet the needs of their customers by providing them with low cost products and services without compromising on the quality of product (Wudhikarn, et al., 2015). This is the case with many manufacturing companies in Ghana today where customers insist on high quality products at low cost.

Most companies, however, perceive high quality of products to mean high cost but it is rather the lack of quality that brings about high cost. This means that high quality products should not necessarily have a high cost. One sure way which is considered by most organizations to improve on customer satisfaction is by improving on the quality of product and service. However, improving the quality of service or a product has accompanying cost implications (Ali, et al., 2013).

Assessment of cost of quality is one key analysis organizations must make to stay in competition. The survival of organizations is largely based on its customers. It is important for an organization to recognize that the customer is key to its success and existence. The customer demands quality products from the organization. The organization incurs certain quality cost in the process of providing quality goods and services. This cost eventually adds up to the final cost of product or service. It is therefore important for the organization to be able to know these areas which contribute to its quality cost and make efforts to reduce this cost. While improving quality, the cost of product or 
service must also be reduced to the lowest possible cost (Ali, et al., 2013). In view of this, companies need to take steps to improve the quality of their products and services and concurrently place emphasis on other areas of cost because while satisfying the customers' needs and requirements there is the need to do so with the minimum cost (Malik, et al., 2016). This reaffirms the assertion that although an organization will invest huge amount into quality activities, the resulting benefits will be enormous.

It is important for organizations to make a conscious effort to assess its cost of quality since it will influence the prices of their products or services and affect their manufacturing performance. The measurement and evaluation of all the costs related to quality is crucial for companies because it goes a long way to help achieve an increase in efficiency and also reduce wasteful expenditure in order to increase profitability (Satanova, et al., 2015). To be able to assess the cost of quality, any quality related cost must be properly monitored, recorded, and reported for action. Several quality gurus have emphasized the need to know the cost of quality as an organization. Knowing the areas to address in order to reduce the cost of quality is a key step to improving manufacturing performance of an organization (Murumkar, et al., 2018). It is worth noting that the cost of quality has a direct effect on the manufacturing performance of the organization.

The cost of quality, which includes cost of conformance and non-conformance, is difficult to be identified using accounting reports and auditing system that have been collected over a time (Barbara, et al., 2008). There has not been enough research in Ghana on the effects of cost of quality on manufacturing performance. This research is intended to bring to bear the need to identify what areas to consider in assessing the cost of quality in a manufacturing company and determine its effect on the manufacturing performance. Many organizations perceive activities that seek to help deliver quality products as expensive, but it is rather the absence of these activities in a manufacturing process that is costly (Murumkar, et al., 2018). Special Ice Company Limited manufactures natural mineral water and carbonated drinks in Ghana. Preliminary search and investigations done with the Managing Director depicts that the company is likely to incur a very high cost of quality. However, the organization has not been able to identify the categories of cost of quality in its manufacturing process and its effect on their manufacturing performance. This research will thus help the organization to identify the categories of cost of quality as well as the elements that contributes to its cost of quality. This research will help the organization to know whether or not they have a good manufacturing performance and also decide on the quality systems to implement in order to improve on quality and reduce the cost of poor quality or non-conformance. This study aims to answer the following questions; why is it necessary for manufacturing companies to assess their cost of quality? What are the categories of cost of quality that need to be assessed and finally what is the effect of failure on cost of quality on manufacturing performance?

\section{Literature Review}

\section{A. Overview of Quality and Cost of Quality}

Quality has been defined in many ways by several quality gurus and organizations. These definitions have varying dimensions and perspectives. Joseph Juran, a quality guru, defined quality as "fitness-for-use" (Stevenson, 2009). This fitness is determined by the customer and implies that if an item is produced or a service is rendered to a 
customer who becomes unsatisfied with the product then the item or service has not met the quality needs of the customer. Juran attaches an element of cost incurred because the needs of the customer have not been met. He was one of the first people to measure the cost of quality and he established that there is a link between reducing the costs of poor quality in other to increase profitability.

Quality has become a paramount factor for nearly all manufacturing companies that seek to capture sufficient orders from their customers (Murumkar, et al., 2018). A research by Murumkar et al. (2018) concludes that any deliberate effort to improve quality will result in an apparent increase in cost of the product since quality has its own cost and that makes it an important task to measure the cost of quality which will inform management about the financial consequences in implementing quality improvement programmes (Murumkar, et al., 2018).

The concept of cost of quality has existed for many years and many research works have been done on this subject of cost of quality. In 1951, Dr. Joseph M. Juran wrote a book titled "Quality Control Hand Book" in which he included a section on cost of quality (Murumkar, et al., 2018).

Armand Feigenbaum in 1961 also wrote extensively on the cost of quality in his book "Total Quality Control" Quality related cost constitutes a significant portion of the total cost and sales of an organization. Armand Feigenbaum in the early 1950 developed a reporting system called "quality cost" when he was an employee with General Electric (Rajeev, et al., 2015).

Philip Crosby (1979), who is a quality guru states that "quality is free". Philip Crosby again measures quality as the cost we incur for not doing things "right the first time". He stresses that by ensuring quality, an organization will be able to reduce cost of non-conformance. He believed in the fact that any level of defect was too high and stressed that every organization should strive to attain "zero defects" (Rajeev, et al., 2015).

Quality is a key competitive factor that is able to differentiate businesses in a global market (Colin, et al., 2015). Companies implement management systems that are able to allow the management to plan, control, secure and improve the quality of goods and services to ensure that the customer requirements are achieved. But in order to be able to achieve this task by management, the associated cost must be budgeted for to sustain these systems. Many people who have criticized quality management have suggested that managing quality does not add any direct value to the success of the company and suggest the cost involved must be kept at the barest minimum (Colin, et al., 2015).

The research by Colin et. al (2015) which was conducted in German Companies in Germany conclude that companies in Germany make a conscious effort to determine their quality-related cost and this makes them able to improve the processes within their companies (Colin, et al., 2015). The research, however, identifies some obstacles in some of the companies which included high cost of data collection and lack of knowledge in the methods for data collection. The research also identifies another problem as the inability to correctly quantify the benefits derived from improving quality. The research thus suggests that it will be prudent to develop suitable methods to reduce the difficulty of collecting data relating to quality cost in order to make it clear the benefits of quality improvement (Colin, et al., 2015). 
In another research by Maja \& Filipovic (2017), the objective was to "expand the level of knowledge about quality costing in current practice" (Maja \& Filipovic, 2017). A study was conducted in 186 companies in manufacturing and service. However, the research was based on companies that were already familiar with cost of quality computation. The results which were obtained from these companies revealed that these companies had a high level of awareness of the relevance of managing cost of quality (Maja \& Filipovic, 2017).

There is not a general conclusion on one single theory for cost of quality (Shahid, et al., 2014). However, available literature generally classifies cost of quality into two main categories as the sum of the cost we incur to achieve conformance and the cost we incur for non-conformance (Shahid, et al., 2014)., The cost of conformance is the cost incurred by an organization to prevent poor quality whiles the cost of non-conformance is the cost incurred when an organization fails to provide products and services that meet customer requirement (Schiffauerova \& Thomson, 2006).

The cost of non-conformance is also sometimes referred to as the cost of poor quality. The cost of poor quality is characterized by the cost that will be eliminated if every activity were always performed without defects or deficiencies or by all activities and processes that do not meet agreed performance and/or expected outcomes (Shahid, et al., 2014).

\section{B. Model on Cost of Quality}

There are several available literatures on the theory of cost of quality which various researchers have delved into. Available literature from research focuses on four cost of quality models namely P-A-F (Prevention-Appraisal-Failure) or Crosby's model, Opportunity Cost models, Process Cost models and ABC models (Shahid, et al., 2014). The research considers the classical P-A-F model as the most used model for assessing cost of quality in an industry. The P-A-F model of cost of quality categorization includes Prevention, Appraisal and Failure (internal and external) costs. The research further states that the basic beliefs of the P-A-F model are that investment in prevention and appraisal activities will reduce failure costs, and that if a further investment is made in prevention activities the appraisal cost will experience a further reduction (Shahid, et al., 2014).

Table 1: Generic Models of Cost of Quality

\begin{tabular}{|l|l|}
\hline Generic Models & Cost/Activity Categories \\
\hline P-A-F model & Prevention + Appraisal +Failure \\
\hline Crosby's Model Opportunity or Intangible & Conformance + Non-conformance \\
Cost Models & Prevention + Appraisal + Failure + Opportunity \\
\hline Process Cost Models & \\
\hline ABC Models & Value Added + Non-Value Added \\
\hline
\end{tabular}

Source: (Shahid, et al., 2014) 


\section{PAF (Prevention-Appraisal-Failure) Model}

Dr. Armand Feigenbaum categorized the cost of quality into Prevention, Appraisal and Failure (PAF) and this has been the most widely used cost of quality model. This categorization has become well known and accepted for computing the costs associated with quality. The failure cost is further divided into the internal and external failure. (Guinot, et al., 2016).

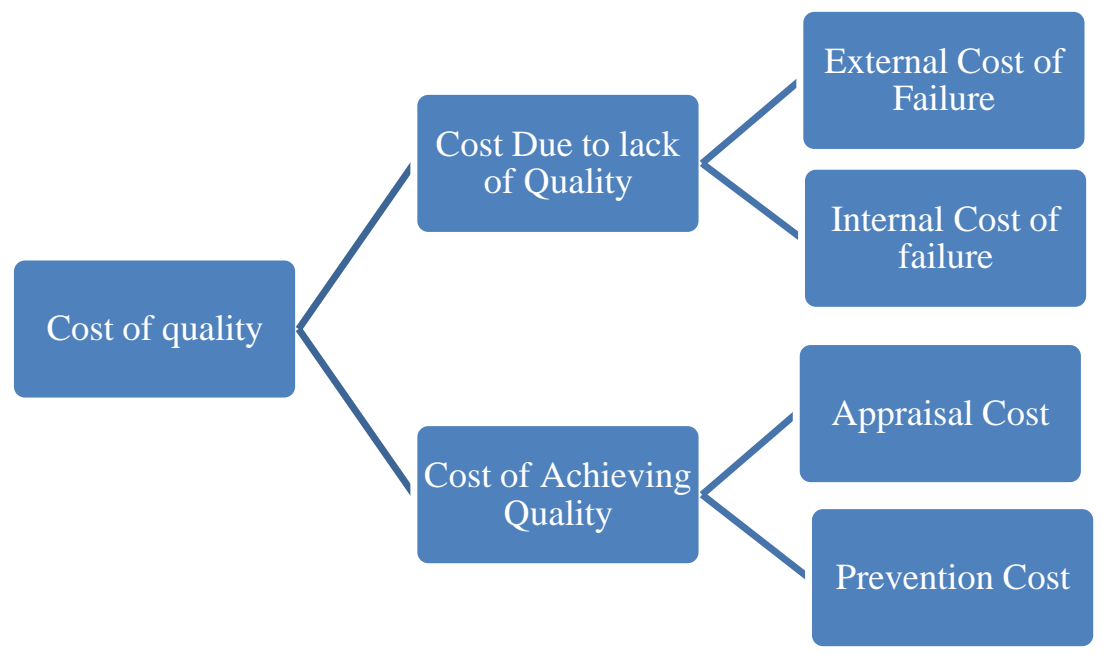

Figure 1: PAF Quality Cost Categories - Source: Author (2019)

\section{Prevention Cost}

Prevention cost is the cost which includes the design, implementation and maintenance of a total quality management system which are aimed at preventing defects from occurring (Stevenson, 2009). Prevention costs are planned and incurred before an operation is enacted. With references to Deming's PDCA cycle, this prevention cost includes all the activities at the planning stage. Selection of appropriate equipment, implementation of systems such as lean supply chain management and Six Sigma programs are all prevention cost which are intended to ensure a quality approach for prevention of poor quality (Evangelos, et al., 2018).

Every activity in an organization must not happen by chance. They should have been thought through thoroughly before implementation (Evangelos, et al., 2018). Example, if an organization wants to start producing a soft drink, it will consider lot of factors before choosing a location to site the factory. The factory should be sited in a location that has been approved by the regulatory authorities. Example is in Ghana, the Environmental Protection Agency, EPA, is a regulatory body that gives approval for siting of factories. If an organization fails to consult these agencies for approvals, they might end up violating some laws which may cause penalty charges or a complete shutdown of the factory due to violation of laws.

\section{Appraisal Costs}

Appraisal costs, however, is the cost related to measuring and inspection activities which are intended to help achieve customer requirements and uncover or assure that there are no defects. It includes the cost for sampling and measuring activities (Evangelos, et al., 2018). It also includes problem analysis, audit and detection activities as 
well as in-process and final inspection and test. The cost incurred for calibration of equipment as well as the test and analysis cost is all classified as appraisal cost (Evangelos, et al., 2018).

There are numerous testing activities that are undertaken in a manufacturing firm. Raw materials that are received for production are taken through standard tests before they are received. Example, if sugar is received at a factory for production the weight is measured, the appearance, taste, clarity among others is tested. These tests are done with equipment. The test equipment is expected to be calibrated at specific timings to ensure that give accurate readings.

\section{Failure Cost}

The Cost of failure is divided into internal and external. The internal cost of failure is the cost associated with failure which is detected within the organization before the final product reaches the customer. This cost is identified before delivery to customers and occurs when products do not meet customer requirement. The products may be retested, reworked or repaired at a cost to the organization. Again, this failure has a cost associated with it as changes in schedules and unplanned man hours are used for corrective activities. Furthermore, process time is lost and there are delays and shortages associated with this failure. This cost may result from "machine settings, faulty equipment, incorrect methods, incorrect processing, carelessness, faulty or improper material handing process" (Stevenson, 2009). The cost associated with this kind of failure include net cost of scrap, rework, labour wastage, re-inspection, raw material wastage, failure analysis, supplier rework among others (Rao, et al., 2010).

External failure cost is the cost incurred when defective products are only detected after products have been delivered to the customer. This cost is incurred through "product returns, warranties, losses due to sales reduction or discounts, reworking of products and loss of customers' good will" (Stevenson, 2009). The cost of external failure has damning implications for the organization especially with the element of loss of customer good will. It is difficult to measure the damaging effect external failure cost can affect the performance of an organization and thus organizations strive to avoid this type of failure (Rao, et al., 2010).

\section{Goal of Assessing Cost of Quality}

A research by (Rajeev, et al., 2015) discusses the goals of assessing quality related costs. It describes cost of quality as a tool which helps to support quality improvement processes in an organisation. The research assigns many goals for implementing cost of quality and states the paramount aim as identification of failure costs and making efforts to reduce it to zero and also to make the necessary investment into the essential prevention activities while reducing the appraisal cost (Rajeev, et al., 2015). Cost of quality can be a tool be an important tool that can be used as a treadle to gain the attention of top management to initiate projects that will lead to quality improvement as top managers are usually influenced by data that is converted to money instead of rates of defects and technical data.

Normally, it takes appraisal activities and customer complaints to reveal internal and external failures in a manufacturing firm. Correction of product defects becomes more expensive when it is detected down the line (Built Environment Project and Assset Management, 2014). Example, it is cheaper to correct the sweetness level (brix) of a beverage when it is at the preparation stage than when the beverage has been filled into a bottle, capped, labelled, 
wrapped and ready to go to the customer. Dale and Plunket (1999) in their research also assigned another goal of cost of quality assessment as being a technique that assist organizations to identify the roles of "manufacturing, marketing, purchase \& design function in quality management efforts” (Rajeev, et al., 2015).

The data representing the quality related cost also helps the organization to define the priorities that need corrective actions. Involvement of management in cost of quality programmes is essential for the success of the programmes. The cost of quality system helps to give a justification for investment into prevention activities which will eventually lower the total quality cost (Rajeev, et al., 2015).

\section{Benefits of Cost of Quality Measurement}

There have been many researches on the benefits of cost of quality measurements. A research conducted by Evangelos et. al (2018) compiles various benefits from available literature (Evangelos, et al., 2018). The research states that an organization will be able to increase the profits it generates from the core business. Cost of quality measurements will also result in an increase in sales volume because the customers will be satisfied with the output and would have an increased preference for that product. Furthermore, the research states that there will be improvement in the product or service quality because the failure which hitherto was present in both the process and the product would have been identified and reduced significantly (Evangelos, et al., 2018).

In addition to the benefits, the researchers continues to state that there will be an increase in a company's competitiveness because there would have been a significant reduction in production cost resulting from a reduction in failure (Evangelos, et al., 2018). Productivity in the organization would also increase because processes would improve. Again, customers and employees alike will be satisfied because they would be able to get value for money. Customer satisfaction will lead to reduced customer complain which implies less external failure (Evangelos, et al., 2018).

The research by Evangelos et al (2018) further suggests that measuring cost of quality will ensure the elimination of all forms of waste from the manufacturing process (Evangelos, et al., 2018). The measurement of cost of quality will also provide management with very vital information needed to make them aware of the extent of their losses and the cost that threatens the survival of their business by identifying the high-cost problem areas (Evangelos, et al., 2018). The organization having identified the high-cost problems will be able to prioritize improvement action that will yield the highest potential payoff.

Finally, further states that measuring cost of quality will help the organization to evaluate the value of the individual quality activities that contribute to the achievement of total quality in the organization. This will increase the overall level of quality awareness in the organization (Evangelos, et al., 2018).

\section{Inter-relations between Cost of Quality Dimensions}

There exists a correlation between the different cost of quality dimensions and many researcherss have conducted researches to understand these relationships. Evangelos et al (2018) compiles a key number of correlations in its research work. As earlier stated, there are three core cost areas that are under study; prevention cost, appraisal cost, failure cost. The failure cost is further divided into internal and external failure. 


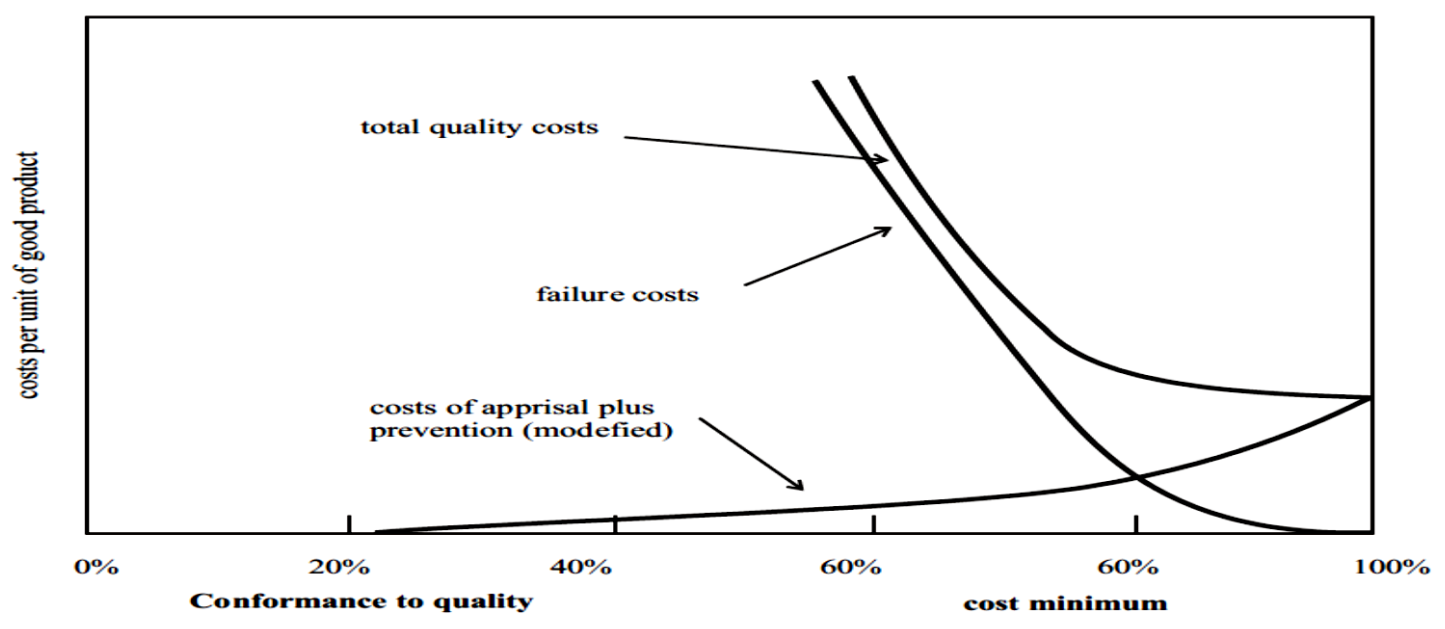

Figure 2: Cost of Quality Model - Modern Source: (Rajeev, et al., 2015)

From the graph in Figure 2 above, there exists a relationship between the prevention cost and the appraisal cost (Rajeev, et al., 2015). There is also a relationship between the internal failure cost and the external cost. The research also shows that there is an inverse relationship between the sum of the prevention cost and the appraisal cost in relation to the failure cost. Thus, an increase in prevention and appraisal cost will result in a reduction in failure cost. There is also a strong negative relationship that exists between the conformance (prevention and appraisal cost) and the nonconformance (internal and external failure cost) (Rajeev, et al., 2015).

From Figure 2, increasing the prevention and appraisal cost will result in a decrease in the total cost of quality. The total cost of quality is the sum of the prevention, appraisal and failure costs. The prevention cost also has the most consequence on the total cost of quality rather than the appraisal cost (Rajeev, et al., 2015). When prevention activities are increased or intensified the need for appraisal is minimized and failure cost is reduced significantly. The relationship between the prevention cost and either the internal failure cost or external failure cost is a strong negative relationship. An increase in prevention cost results in a reduction in both internal and external failure (Rajeev, et al., 2015).

Finally, the graph in Figure 2 shows that there exists a strong negative inverse relationship between the appraisal cost and the internal failure cost. The same inverse relationship is seen between the appraisal cost and the external failure cost.

\section{Conceptual Framework}

The conceptual framework encapsulates the relationship that exists between the study variables. The categories of cost of quality that this research will seek to assess will be the Prevention, Appraisal and failure cost and the effects which each of the categories has on manufacturing performance. The independent variables thus will be the categories of cost of quality while the dependent variable will be the manufacturing performance. Figure 3 shows the conceptual framework 


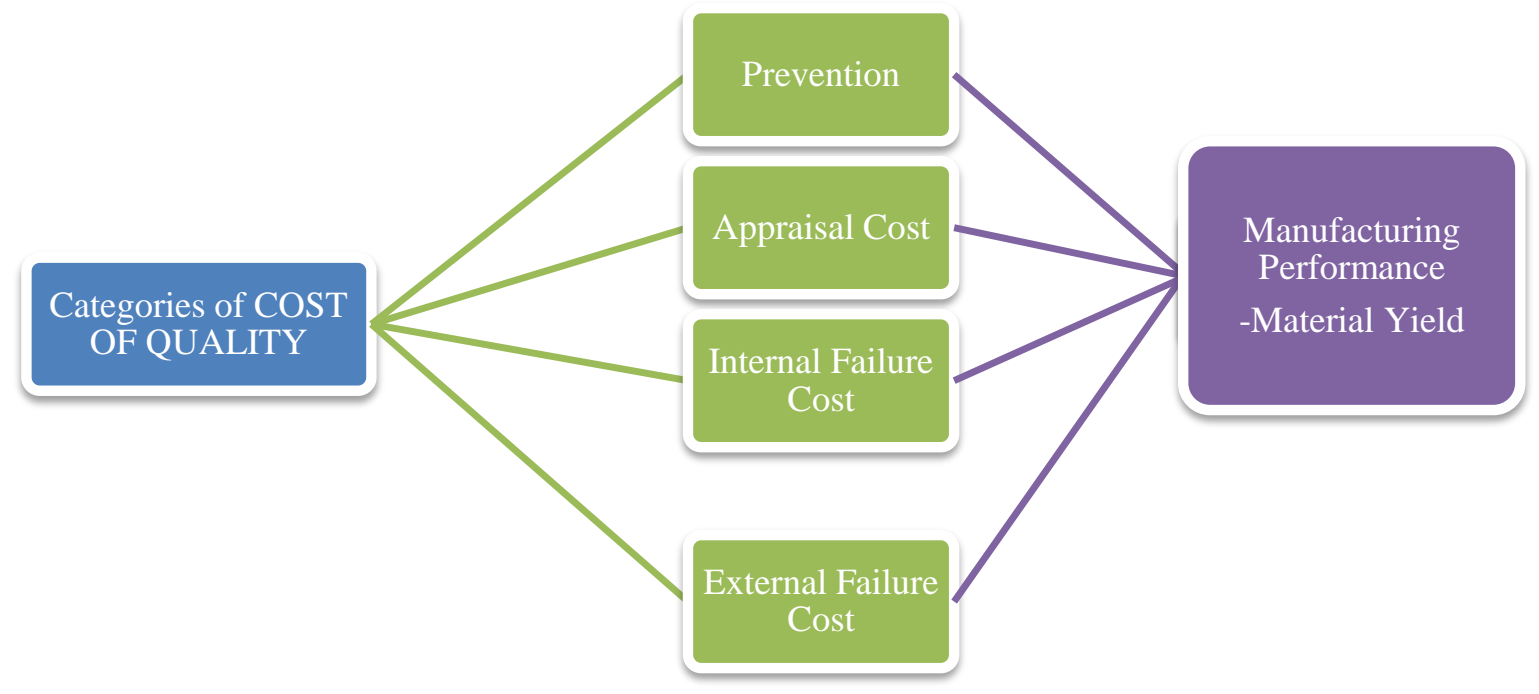

Figure 3: Conceptual Framework Source: Authors Design (2020)

The researchers arrived at this conceptual framework after delving in several research works and realized that the assessment of cost of quality and its effect on manufacturing performance is an area that has not been delved into especially in Ghana.

\section{Methodology}

\section{A. Research Approach and Design}

A descriptive research design method was used for this study by the researchers. Information was gathered from what currently exist in the manufacturing industry. According to (Fox \& Bayat, 2007) descriptive research identifies and brings to bear current issues or problems by using data collection that helps to describe the situation in a more complete way which would not have been possible without the application of this method (Research Methodology, 2018). This approach helped to identify and understand which category of cost of quality affected the organization's quality cost. This descriptive approach allowed for the use of both qualitative and quantitative. Descriptive research design is used when the data collected is used to describe persons, organizations or phenomena and this design also gives enough protection against bias and maximized reliability.

Qualitative research method allows every participant to be considered as unique (Creswell, 2007). The participants can narrate their personal experience regarding the assessment of cost of quality in the manufacturing firm. A semi-structured interview method was conducted with one of top management staff to better understand the operations of the organization.

\section{B. Population and Sample size}

A research population generally refers to a large collection of individuals who are the key focus of the scientific research (Mugenda \& Mugenda, 2003). The target population for this research is the total number of workers at Special Ice Company Limited, carbonated soft drink factory at Oyarifa. The population thus was composed of 140 workers. 
The sampling technique involve the procedures that were applied to get a sample from the population (Mugenda \& Mugenda, 2003). The sample size included top and middle level managers of the organization. It also included the various levels of supervisors and quality assurance officers in the organization. Technicians, Operators Production assistants were also included in this research. This was a purposive sampling approach and the "elements selected for the sample were chosen by the judgment of the researchers" (Research Methodology, 2018). Questionnaires were administered to 80 respondents who were chosen randomly from all the various departments in the organization.

The data collection instruments that were used for the study included self-administered questionnaires and semi-structured interviews with top management of the manufacturing firm. This data collected was considered as a primary source. The questionnaire items were derived from the problem specification. These tools were employed to facilitate the data collection process as and when the use of any one of them became necessary. According to Nichols et al. (2013) a questionnaire is a tool that is used to collect and record information about a case that is of interest to the respondents.

The researchers also had the benefit of being on the field and observed the operations of the firm and this enabled the researchers to gain a better understanding of the underlying issues with regards to how the cost of quality is assessed and the effects it had on the manufacturing performance of the company.

\section{Discussions}

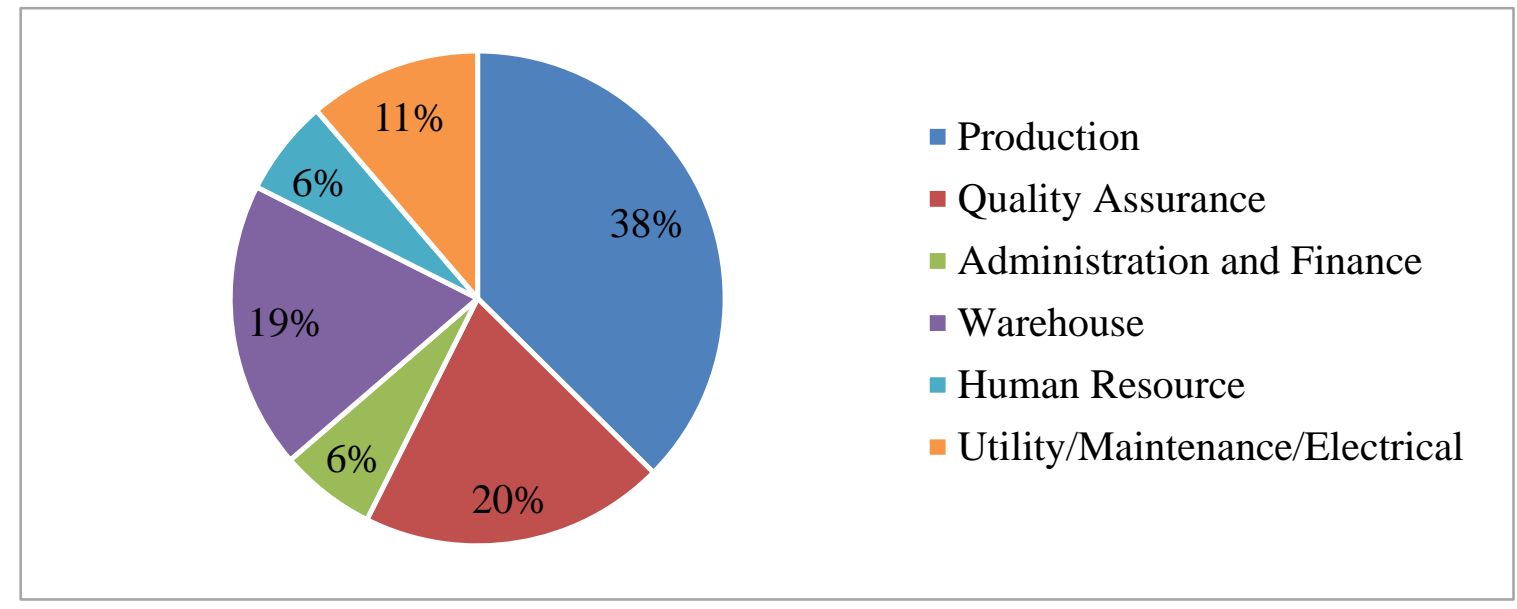

Figure 4: Descriptive Statistics

Table 2: Descriptive Statistics

\begin{tabular}{lll}
\hline Factors & Mean & \pm SD \\
\hline Cost of Prevention $(\mathbf{C P})$ & & \\
To what extent does your company practice quality planning? & 2.73 & \\
(CP1) & & 0.136 \\
To What extent does your company indulge in supplier 2.54 & \\
\hline
\end{tabular}


capability surveys (CP2)

Does your organisation embark on quality improvement team 2.81

meetings? (CP3)

To what extent does your organisation embark on quality 2.51 improvement projects? (CP4)

Does your organisation embark on quality education and 2.64

training for its employees? (CP5)

Does your organisation perform new product reviews? (CP6) 2.79

Cost of Appraisal (CA)

Does your company perform inspection/test on purchased raw 3.83 materials? (CA1)

Does your organisation perform in-process and final 3.86 inspection/test? (CA2)

Does your organisation perform product and process audits? 3.54

(CA3)

Does your organisation perform calibration of measuring and 3.70 test equipment? (CA4)

\section{Cost of Internal Failure (CIF)}

How often does your organisation scrap materials/products? 3.14

(CIF1)

How often does your organisation rework materials/products? 3.08 (CIF2)

How often does your organisation re-inspect 3.20 materials/products? (CIF3)

How often does your organisation re-test materials/products? 3.36

(CIF4)

Cost of External Failure (CEF)

To what extent does your organisation receive customer 2.64 0.716 complain? (CEF1)

To what extent does your organisation receive product returns $\quad 2.35$ 0.658 from customers? (CEF2) 
To what extent does your organisation receive warranty 2.05 0.825 claims? (CEF3)

To what extent does your organisation do product recalls? 2.09

(CEF4)

Manufacturing Performance (MP)

To what extent is the yield of packaging materials affected by 3.05 poor quality? (MP1)

To what extent is the yield of syrup affected by poor quality? 3.05

(MP2)

To what extent is the machine efficiency affected by poor 3.31 quality? (MP3)

To what extent are products recalled from trade? (MP4)

To what extent are products quarantined after production? $\quad 2.69$ (MP5)

To what extent does downtime affect achievement of 3.89 production targets? (MP6)

To what extent does machine breakdown affect production 4.05 performance? (MP7)

Cost of Conformance (CC)

To what extent will prevention and appraisal reduce defects? 4.16 (CC1)

To what extent will prevention and appraisal reduce returned 4.06 goods? (CC2)

To what extent will prevention and appraisal reduce customer 4.11 complains? (CC3)

To what extent will prevention and appraisal reduce overall 4.19 costs of quality? (CC4)

To what extent will prevention and appraisal reduce legal 4.04 cost? (CC5)

To what extent will prevention and appraisal reduce employee 3.99 turnover? (CC6) 
To what extent will prevention and appraisal reduce owner $4.24 \quad 0.86$

and management stress? (CC7)

Preventing Poor Quality of Product (PPQP)

To what extent will elimination of cost of failure increase 4.08

sales and profitability? (PPQP1)

To what extent will elimination of cost of failure increase 4.26

production output? (PPQP2)

To what extent will elimination of cost of failure increase 3.98

customer satisfaction? (PPQP3)

To what extent will elimination of cost of failure increase 3.99

market share and competitive edge? (PPQP4)

To what extent will elimination of cost of failure increase 4.28 employee satisfaction? (PPQP5)

Source: Author's Estimation, 2019 Categories of Cost of Quality That Needs to be Assessed

Table 2 presents characteristics of the data acquired from the survey. It shows averagely the extent to which participants associate the attributes to cost of quality. Participants were required to rate the extent of agreement with the questions asked. Using a Likert scale of 1-5 where

\section{1 is Not at all}

\section{2 is Little Extent}

\section{3 is Moderate Extent}

\section{4 is Great Extent}

\section{5 is Very Great Extent}

Out of the six (6) items used in measuring cost of prevention, participants moderately associated with all the item to cost of prevention in the organisation. This is seen from the responses for questions CP1 to CP6 in table 2 above. Participants were of the view that quality planning, supplier capability survey, quality improvement team meetings, quality improvement projects, quality education and training for employees, product review activities which are all prevention activities are given average attention by the organisation.

However, participants agree to a great extent that the company attaches a great level of importance to cost of appraisal activities. Appraisal activities like inspection and testing of purchased raw materials and in-process outputs, process audits and calibration of measuring and test equipment were all above average according to the participants. This trend depicts that appraisal activities were more evident than prevention activities. This is seen from their responses to question CA1 to CA4 in table 2 above. 
In terms of cost of internal failure, participant moderately associate the items such as scrap materials/products, rework materials/products, re-inspect materials/products, re-test materials/products to the organisation. Internal failure which results in scrap, rework, re-inspection and retesting of materials also saw a moderate response by the participants. Retesting activity however was more prominent. This is seen from their responses to question CIF1 to CIF4 in table 2 above.

Participants also agree moderately to the items under the cost of external failure. External failure which are as a result of customer complain, product returns, warranty claims and product recalls received a moderate response with customer complains being more prominent. This is seen from their responses to question CEF1 to CEF4 in table 2 above.

\section{What is the Effect of Prevention, Appraisal and failure on Manufacturing Performance?}

Participants associate low manufacturing performance greatly to downtime of equipment and breakdown of machines but moderately agree to yield of packaging materials, yield of syrup, product quarantine affects manufacturing performance. Product recall on the other hand they believe did not have any association with manufacturing performance. This is seen from their responses to question MP1 to MP7 in table 2 above.

\section{Why is it Necessary to Assess Cost of Quality?}

As earlier stated in the literature review, the cost of conformance is the sum of the cost of prevention and appraisal. The participants associated all the items under cost of conformance to have a great impact on improving the cost of quality within the organisation. The participants agreed to a great extent that increasing the cost for activities of prevention and appraisal will reduce the quantity of returned goods and customer complains. The participants also generally agreed to a great extent that overall cost of quality will reduce, legal cost will reduce, employee turnover will reduce and also owner and management stress will be reduced when the cost activities for prevention and appraisal are increased. This is seen from the responses of the participants for question CC1 to CC7 in Table 2 above. Implementation of strong prevention and appraisal activities will ensure that scrap, reworks, re-testing and re-inspection is reduced. Again, customer complaints, product returns and product recalls will be reduced significantly because prevention and appraisal activities are intensified.

Finally, responses for questions PPQP1 to PPQP5 in Table 2 reveals that elimination of cost of failure greatly improves sales and profitability, production output, customer satisfaction, increase market share and competitive edge as well as increases employee satisfaction. As discussed earlier in the literature review chapter, the cost of poor quality is also known as the cost of nonconformance.

\section{Factor Analysis}

\section{Exploratory Factor Analysis}

Exploratory factor analysis was done using the principal component analysis with the varimax rotation to identify the structure of the proposed model. Exploratory factor analysis (EFA) was used to find the number of factors influencing the key latent variables (DeCoster, 1998). To measure the key indicators that can appropriately 
measure construct understudy, a data reduction strategy was employed. Kaiser-Meyer-Olkin (KMO) measure of sample adequacy and Bertlett's test of Sphericity was conducted to determine whether significant relationship exist amongst the variables understudies. This is depicted in table 3 below.

Table 3: KMO and Bartlett's Test

\section{KMO and Bartlett's Test}

\begin{tabular}{lll}
\hline Kaiser-Meyer-Olkin Measure of Sampling Adequacy. & 0.676 \\
Bartlett's Test of Sphericity & Approx. Chi-Square & 2161.859 \\
& df & 666.000 \\
& Sig. & 0.000
\end{tabular}

Source: Author's Estimation, 2019

From Table 3, the KMO and Bartlett's test recorded $(\mathrm{KMO}=0.676, \mathrm{df}=45, \mathrm{p}<0.05)$ shows the adequacy of sampling and applicability of factor analysis (Hair, Anderson, Tatham and Black, 1998) and Bartlett's test of Sphericity (Approx.: Chi-Square $=2161.859, \mathrm{df}=66, \mathrm{sig}=0.000$ ). The result however confirms the rationale for conducting a factor analysis on the dataset.

\section{Factor Loading and Reliability Test}

The reliability of the questionnaire for the study was done using the Cronbach's Alpha test. This test was used to the test the internal constituency of the data from the instrument. Also, to check if data from the instrument can measure all the variables of interest understudy. A data with a good internal consistency has an alpha greater than 0.5 .

Table 4: Reliability Test

\section{Reliability Statistics}

\begin{tabular}{lll}
\hline Cronbach's Alpha & Cronbach's Alpha Based on N of Items \\
& Standardized Items
\end{tabular}

0.805

0.819

37

Source: Author's Estimation, 2019

From table 4, the Cronbach's Alpha of 0.819 and this indicates a high level of internal consistency for our scale with the sample used for the study. The factor loading analysis on the other hand was used to determine factor which will be considered appropriate for further analysis. An eligible variable are the ones with a factor loading greater than 0.5 and an eigenvalue of greater or equals to 1 .

For factor analysis, the principal component analysis complimented with the varimax approach was used to extract the requisite indicators for further analysis. A total of 20 indicators were evaluated using this approach. Out of the 37 indicators, 2 indicators were dropped because they failed to achieve the required factor loading and eigenvalue 
caveat (Hair et al., 2010; 2014). Table 5 below shows the result from the factor loading analysis indicating the 35 of the variables that loaded perfectly on the seven (7) factors understudies. The first which is cost of prevention, measured by six (6) indicators, second which is cost of appraisal, measured by four (4) indicators, the third which is cost of internal and external failure, measured on four (4) indicators each, measure of performance, measured on five(5) indicators, cost of conformance, measured on seven (7) indicators and preventing poor quality of product, measured on five(5) indicators.

However, their internal consistency of the variables was also measured using the Cronbach's alpha coefficient.

Table 5: Hierarchical Multiple Regression Analysis

Model I $\quad$ Model II

\section{(Constant)}

Independent Variable

Cost of Prevention

Cost of Appraisal

Cost of Internal Failure

Cost of External Failure

Cost of Conformance

Interactive

Cost of Conformance* Cost of Prevention

Cost of Conformance*Cost of Appraisal

Cost of Conformance* Cost of Internal Failure

Cost of Conformance*Cost of External Failure

$\mathbf{R}^{2}$

$\mathbf{R}^{2}$ Adjusted

$\Delta R^{2}$
2.024

1.476
$0.025(0.545)$

$-0.112(-1.811)^{+}$

$-0.011(-0.169)$

$0.371(4.800) * * *$

$0.17(3.359) * *$

Source: Author's Estimation, $2019\left({ }^{+} \mathrm{P}<.10,{ }^{*} \mathrm{p}<.05 .,{ }^{* *} \mathrm{p}<.01 ., * * * \mathrm{p}<.001\right)$

The result shows that model 1 has an R-square of 0.068 , this implies that $6.8 \%$ of variability in the manufacturing performance can be accounted for by cost of prevention, cost of appraisal, cost of internal and external failure. Model 2 has an R-square of 0.077 and indicates a change of 0.009 and this explains how the adoption of cost of conformance can moderate the outcome between the independent variable and the manufacturing performance. Also, the independent variables cost of appraisal and cost of external failure have a statistically significant impact 
on the manufacturing performance i.e. ( $\beta=-0.112$ and $0.371, p<0.10$ and $p<0.01$ ) respectively on manufacturing performance.

The researchers had the opportunity to observe the operational activities of the firm. The firm produces carbonated soft drinks for the Ghanaian market and for export to Burkina Faso. The firm has two production lines with a rated production capacity of 18,000 bottles per hour each. The organization sources its raw materials from local factories in Ghana. Some of the materials purchased in Ghana include sugar, preforms, caps, labels, adhesive, shrink film, carbon dioxide, laboratory chemicals and reagents, among others. The Organization also purchases some materials from Europe which include preservatives, acidulants, stabilizers, sweeteners, concentrates, flavours, thickeners, among others. All purchases are conducted by a purchasing department.

All materials received go through rigorous quality checks to ascertain its conformance to approved standards before being received for production. There are standard operation procedures which are followed to perform these checks. Any nonconformance recorded with materials is recorded and actions taken immediately. The materials that pass the material received test and checks are received into the raw material warehouse - proper inventory records are kept on these materials. The materials have different storage conditions which are strictly adhered to. Some of the materials like the flavours and concentrates are temperature sensitive and are stored in industrial refrigerators with controlled temperatures. Others are stored in ambient temperature and in a clean dust-free environment - example is the caps, preforms, preservatives, acidulants, thickeners, among others.

The organization has a well-structured quality assurance department which plays a key role in the adherence to quality standards. The organization is HACCP (Hazard Analysis and Critical Control Point) certified. This certification is awarded by the Food and Drugs Authority in Ghana. This certification is a food safety management and product quality programme. This certification is an international standard and it defines the requirements needed for an effective control of food safety (SGS, 2019).

Raw materials which have been received into the warehouse are released to the production hall for production based on authorized requisition from the in-charge. The raw materials are released using a manual system of material request. The material usage is recorded and reported on daily basis by the production supervisors. The production process starts with the preparation of concentrated syrup which is prepared based on a specific recipe. The syrup is prepared using vessels and pipes that are made of stainless-steel material. Before the syrup is prepared, a process of cleaning called CIP (cleaning in place) is used to clean these pipes and vessels. The CIP process uses a water-based solution composed of food grade reagents which are prepared at a standard concentration, temperature and passed through these vessel and pipes at a required pressured for a required time.

The prepared syrup is then diluted in equipment and food grade carbon dioxide gas is impregnated into the diluted syrup to a required brix and carbonation level. The beverage is then filled into freshly blown bottles which prior to filling are washed with pressurised clean ozonated water to remove any solid particles and also disinfect the bottles. The filled bottles are then capped and labeled. The labeled products are then packaged in desired numbers by means of wrapping a shrink film around the bottled products. The packaged products are then released to the finished 
goods for sale to the market. Every finished product that leaves the finished goods warehouse are properly accounted for.

In the manufacturing processes, inspection and testing are conducted by the quality assurance officers at various stages to confirm that the products meet the quality standards at every stage of the process. Documented records are filed to conform to set standards.

The production department also takes records on machine performance, downtime, material wastage, faults records and files them accordingly.

There is no integrated software for use in the production process. However, excel spread sheets are created to record material yields. Key among these yield computations are cap yield, bottle yield, syrup yield, carbon dioxide yield, label yield, shrink film yield. The essence of computing these yields is to be able to determine the level of waste generated in the process of production. The wastages are calculated by a simple method of comparing the quantity of finished goods produced to the quantity of materials used -the difference in quantity is the wastage. For example, each bottle has one cap so if at the end of production 200 bottles are produced and 210 caps were used then the waste becomes 10 caps. Although these wastages are quantified, monetary value is not attached to these wastes and even when they are, they are not formally communicated to the entire staff.

There is also a monthly stock taking exercise which is organized by the finance department. The stock of raw materials and finished goods are checked to ascertain the stock levels and the monetary value of the stock. However, there is the absence of an analysis to determine whether the stocks have been used appropriately.

\section{Semi-Structured Interview Session with the Managing Director}

A semi-structured interview was conducted as part of the methodology for collecting primary data concerning the subject area. Before the interview, an interview guide was prepared and reviewed by the researchers to ensure that the questions were detailed enough to address the research questions. Top managers as well as heads of department were considered for this interview. However, it was concluded by researchers to interview the highest manager in the hierarchy due to time constraints.

The result from the interview with the Managing Director revealed that he had a clear understanding of what quality means in relation to manufacturing. He defined quality as conformance to customer and regulatory specifications. He agreed that the customer is key to the success of the organization and their needs must be well understood and delivered. He also believed that whatever product that is produced must also meet the standards set by the Ghana Standard Authority (GSA) as well as the Food and Drugs Authority (FDA) and the processes must also conform to Environmental Protection Agency (EPA) Standards. The Managing Director also agreed that quality comes at a cost. However, he was not immediately familiar with the term cost of quality.

The Managing Director was not immediately familiar with the categories for cost of quality as prescribed by Armand Feigenbaum, the P-A-F model. The researchers took time to explain to him what was meant by the PAF model. Based on the understanding he had about this model, it was evident that the organization was not able to clearly segregate their cost of quality into prevention, appraisal, and failure cost because they were not familiar with 
the concept. The data for cost of quality was not collected, measured and analyzed in the organization. Because the cost of quality is not measured, the organization did not know which areas contributed the highest to the cost of quality.

From the interview, the Managing Director agreed that the organization was not very competitive in the market in terms of the price at which they sold their products. Although the organization had a high production cost, they were unable to increase their selling price to enable them to make the required profits because of the fear of receiving less patronage because of their high price. The reasons which he assigned for the high production cost was because of frequent machine breakdown and high wastage of material resulting from faulty equipment. The frequent machine breakdown was because of the age of the machines as well as the poor attitude of some workers towards maintenance as well as a lack of requisite technical know-how on the part of some technicians and operators. He also agreed that unavailability of requisite spare parts was also another reason for their high downtimes which results in low production volumes.

The Managing Director confirmed that the current waste of materials was too high. The Managing Director however, could not put a definite figure to this waste level. Although the wastage level allowed by the organization, internal benchmark, was $2 \%$, it was not well communicated to all workers. The production is unable to meet the set yield targets.

The Managing Director revealed that even though the organization did not collect data on the cost of quality, they were aware of the many benefits they could gain from performing this task. The Managing Director agreed that once the organization makes efforts to measure these costs and properly categorize these costs, they will be able to make decisions on which areas to improve in order to reduce their failure cost. He also agreed that by investing in preventive and appraisal methods they are likely to reduce the wastages in the organization there by improving the yield. He attributes their low material yields mainly to the presence of high wastages. He believes that when this waste is eliminated or reduced, the organization can stay more competitive in the market.

Finally, the Managing Director agreed that measuring cost of quality had tremendous benefits which they have not yet enjoyed since they had not paid attention to it. The Managing Director agreed to that as top management, they needed to initiate this process of quality costing and show a high level of commitment to the implementation and ensure continuous improvement in the programme for its success. Finally, he agrees that without the commitment of the top management, the benefits of measuring and analyzing cost of quality would not be properly harnessed.

\section{Conclusion}

On daily basis, production firms seek to enhance their manufacturing performance and Ghanaian firms are no exception to this pursuit. In so doing firms end up employing different strategies to enhance their cost of quality and hence their manufacturing performance. Failure to monitor their manufacturing performance, a firm in this case suffer financial distress and worse still, suffer closure which is very detrimental to any given country. The research therefore aimed at assessing the cost of quality and its effect on manufacturing performance of manufacturing companies in Ghana. The study focused on Special Ice Company Limited as a case study. The study employed 
three categories namely; cost of prevention, cost of appraisal and cost of failure as a proxy for cost of quality on the manufacturing performance. A sample of 80 participants were randomly selected for this study. Primary data was collected and analysed. The findings show that the cost of quality element like cost of external failure and cost of appraisal had a statistically significant impact on the manufacturing performance of the company.

In line with the objectives and findings from the study, the researchers make the following recommendations.

The case organization could make a conscious effort to sensitize employees to understand the cost of quality and its implications on the manufacturing performance of the company.

Top Management could get actively involved and make a conscious effort to incorporate the cost of quality in their decision-making process and get all staff to align and adhere to it.

The company is encouraged to pay close attention to complains that comes from customers and act on it to improve on the products. The company is always encouraged to appraise their production processes and ensure their entire staff adhere to it as failure to do so impacts negatively on the manufacturing performance of the company. From the general objectives of the study and research findings, the researchers suggests further studies be done on the very same topic but to cover a wider scope such as all the manufacturing industries in Ghana to confirm if the research findings of this study will be the same for the further studies based on the other performance perspectives.

\section{References}

Ali, K., Jamal, M. \& Mahdi, A. Z., 2013. Cost of Quality and Quality Optimization in Manufacturing. European Online Journal of Natural and Social Sciences, 2(3), pp. 1070-1081.

Arvaiova, M., Aspinwall, M. \& Walker, S., 2009. An Intial survey on cost of quality programmes in telecommunications. The TQM Journal, 21(1), pp. 57-71.

Barbara, C., Eutropio, E. S. C. \& Catunda, R., 2008. Modeling the Cost of Poor Quality. Proceedings of the 2008 Winter Simulation Conference, 7-10 December, pp. 1437-1441.

Bryman, A. \& Bell, E., 2007. Business Research Methods. 2nd ed. London: Oxford University Press.

Built Environment Project and Asset Management, 2014. Determining the cost of poor quality and its impact on productivity and profitability. 4(3), pp. 296-311.

Colin, R., Falk, B., Marie, D. \& Roland, J., 2015. Do Quality Cost Still Matter. Total Quality Management and Business Excellence, 26(10), pp. 1071-1082.

Creswell, J. W., n.d. Qualitative. [Online].

Dahlgaard, J., Kristensen, K. \& Kanji, G. K., 1998. Fundamentals of Total Quality Management: Process Analysis and Improvement. 1st ed. London: Chapman \& Hall.

Djekic, I., Zaric, V. \& Tomic, J., 2014. Quality Cost in a Fruit Processing Company: Case Study of a Serbian Company. Quality Assurance and Safety of Food and Crops, VI(1), pp. 95-103. 
Asian Journal of Basic Science \& Research

Volume 2, Issue 3, Pages 01-22, July-September 2020

Emerald Group Publishing Limited, 2007. Cost of quality usage and its relationship to quality system maturity. International Journal of Quality and Reliability Management, 24(2), pp. 121-140.

Evangelos, P., Christina, D., Fotis, V. \& Nancy, B., 2018. Cost of Quality Measurement in Food Manufacturing Companies: The Greek Case. International Journal of Productivity and Performance Management, 67(9), pp. 1882-1900.

Farah, M. \& Nina, S., 2016. Factors Affecting Profitability of Small Medium Enterprises (SMEs) Firms listed in Indonesia Stock Exchange.. Journal of Economics, Business and Management, 4(2), pp. 132-137.

Feigenbaum, A. V., 1961. Total quality control. New York: McGraw-Hill.

Fox, W. \& Bayat, M., 2007. A Guide to Managing Research. s.1.:Juta Publications.

Guinot, J., Evans, D. \& Badar, M. A., 2016. Cost Quality Consideration Following Product Launch in a Present Worth Assessment. International journal of Quality and Reliability Management, 33(3), pp. 399-413.

Harrington, J., 1987. Poor Quality Cost. New York: Marcel Dekker Inc., ASQC Quality Press.

Juran, J. M., 1951. Juran's Quality Control Handbook. New York: McGraw-Hill.

Mahmood, S. \& Kureshi, N. I., June 2015. A literature Review of the Quantification. Journal of Quality and Technology Management, XI(1), pp. 1-24.

Maja, G. \& Filipovic, J., 2017. Quality Costs in Practice and and Analysis of the Factors affecting Quality Cost Management. Total Quality Management and Business Excellence.

Malik, T. M., khalid, R., Zulqarnain, A. \& Iqbal, S., 2016. Cost of Quality: Findings of a Wood Products Manufacturer. The TQM Journal, 28(1), pp. 2-20.

Mugenda, O. \& Mugenda, A., 2003. Research Methods: Quantitative and Qualitative Methods. Nairobi: ACTs.

Murumkar, A. B., Teli, S. N. \& Loni, R., 2018. Framework for Reduction of Quality Cost. International Journal for Research in Engineering Application and Management (IJREAM), pp. 156-162.

Muya, T. W. \& Gathogo, G., 2016. Effect of Working Capital Management on Profitability of Manufacturing Firms in Nakuru Town, kenya.. International Journal of Economics, Commerce and management, 4(4), pp. $1082-1105$.

Niresh, J. \& Velnampy, T., 2014. Firm Size and Profitability: A Case Study of Listed Manufacturing Firms in Sri Lanka. International journal of Business and Management, 9(4), pp. 57-64.

Rajeev, T., Anish, S. \& Rajiv, K. G., 2015. A Comprehensive Review on Cost of Quality. VIVE CHAN International Journal of Research, 6(1), pp. 70-88.

Rao, A. et al., 2010. Total Quality Management: A Cross Functional Perspective. In: New York, NY: John Wiley \& Sons, pp. 119-163.

Research Methodology, 2018. Methodology: Descriptive Research. [Online] 
Available at: https://research-methodology.net [Accessed 20 November 2018].

Retnari, D., Rapi, A. \& Nilda, A., 2010. The Measurement of Quality Performance with Sigma Measurement and Cost of Poor Quality as a Basis for selection Process for Quality Improvement.. Hong Kong, IMECS.

Satanova, A. et al., 2015. How Slovak Small and Medium Manufacturing Enterprises Maintain Quality Costs; An Empirical Study and Proposal for a Suitable Model. Total Quality Management and Business Excellence, 26(11), pp. 1146-1160.

Schiffauerova, A. \& Thomson, V., 2006. A reveal of research of cost of quality models and the best practices. International Journal of Qualityh and Reliability Management, 23(4), pp. 647-669.

Setijono, D. \& Dahglaard, J., 2008. The value of quality improvements. International Journal of Quality and Reliability Management, 25(3), pp. 298-312.

SGS, 2019. SGS. [Online] Available at: www.sgs.com [Accessed 4 May 2019].

Shahid, M., Syed, M. A., Kamalesh, P. \& Nadeem, I. K., 2014. Determining the Cost of Poor Quality and its Impact on Productivity and Profitability. Buit Environment Project and Asset Management, 4(3), pp. 293-311.

Special Ice Company Limited, 2018. About Us:Special Ice Company limited. [Online]

Available at: http://www.specialicelimited.com [Accessed 24 August 2018].

Stevenson, J. W., 2009. Operations Management. 10th ed. new York: McGraw Hill/Irwin.

Wudhikarn, R., Chakpitak, N. \& Neubert, G., 2015. An Analytical Network Process Approach for the Election of Green Marketable Products. Benchmarking: An Internaltional Journal, 22(6), pp. 994-1018. 